\title{
Auroral ionospheric E region parameters obtained from satellite- based far-ultraviolet and ground-based ionosonde observations - effects of proton precipitation
}

\author{
Harold K. Knight \\ Computational Physics, Inc., Springfield, VA 22151, USA \\ Correspondence: Harold K. Knight (knight@ cpi.com) \\ Received: 25 July 2019 - Discussion started: 19 August 2019 \\ Revised: 8 December 2020 - Accepted: 9 December 2020 - Published: 28 January 2021
}

\begin{abstract}
Coincident auroral far-ultraviolet (FUV) and ground-based ionosonde observations are compared for the purpose of determining whether auroral FUV remote sensing algorithms that assume pure electron precipitation are biased in the presence of proton precipitation. Auroral particle transport and optical emission models, such as the Boltzmann 3-Constituent (B3C) model, predict that maximum E region electron density $(\mathrm{NmE})$ values derived from auroral Lyman-Birge-Hopfield (LBH) emissions, assuming electron precipitation, will be biased by up to $\sim 20 \%$ (high) for pure proton aurora, while comparisons between LBH radiances and radiances derived from in situ particle flux observations (i.e., Knight et al., 2008, 2012) indicate that the bias associated with proton aurora should be much larger. Surprisingly, in the comparisons with ionosonde observations described here, no bias associated with proton aurora is found in FUVderived auroral NmE, which means that auroral FUV remote sensing methods for $\mathrm{NmE}$ are more accurate in the presence of proton precipitation than was suggested in the aforementioned earlier works. Possible explanations for the discrepancy with the earlier results are discussed.
\end{abstract}

\section{Introduction}

Auroral particle transport and optical emission models, such as the Boltzmann 3-Constituent (B3C; Strickland et al., 1993) model, predict that proton aurora is $\sim 50 \%$ more efficient in producing $\mathrm{N}_{2}$ Lyman-Birge-Hopfield (LBH) emission than electron aurora, but comparisons between satellitebased auroral far-ultraviolet (FUV) and in situ particle flux observations have indicated that the difference is actually much greater than $50 \%$ (Knight et al., 2008, 2012). Such a bias would have a detrimental effect on auroral FUV remote sensing algorithms that assume pure electron precipitation. In this study, we look for a biasing effect of proton precipitation on the auroral maximum ionospheric $\mathrm{E}$ region electron density parameter, $\mathrm{NmE}$, derived from LBH radiances, by comparing FUV observations with coincident observations of the E region by high-latitude, ground-based ionosondes. Supporting information for this study is given in a recent paper (Knight et al., 2018), including details about instruments, our auroral FUV remote sensing algorithm (assuming pure electron precipitation), and ionogram interpretation methods. Knight et al. (2018) also gives extensive comparison results for the coincident FUV and ionosonde observations, but omits an investigation of the statistical effect of proton aurora, which is left for this paper.

Although proton aurora contributes only $\sim 15 \%$ of the total energy deposited by auroral precipitation into the upper atmosphere (Hardy et al., 1989), it is often an important source of $\mathrm{E}$ region ionization, especially towards the equatorward boundary of the auroral oval in the pre-midnight sector (Galand and Richmond, 2001). Galand and Lummerzheim (2004) pointed out that the different ion production and emission profiles of electron and proton aurora will cause errors in LBH-based auroral remote sensing methods that assume electron precipitation. Besides the two Knight et al. (2008, 2012) studies mentioned above, Frey et al. (2001), Gérard et al. (2001), and Coumans et al. (2002) also compared FUV and in situ observations. These earlier works are discussed in Knight et al. (2008). 
In studying possible biases associated with proton aurora, one advantage of comparing FUV data with E region observations instead of in situ particle flux is that $\mathrm{E}$ region comparisons eliminate the uncertainty associated with possible differences in calibration errors between electron and ion (treated as proton) flux detectors. We opted to use ionosonde instead of incoherent scatter radar (ISR) observations of the E region because ionosondes operate continuously and offer thousands of observations that are made within a few minutes of satellite overpasses of ground stations. We have made auroral FUV-ionosonde comparisons for approximately 1000 overpasses of ground stations, which is larger than any previous study of coincident FUV and ground-based observations of the $\mathrm{E}$ region.

FUV observations from three instruments aboard three different satellites were included in the study, namely the NASA Thermosphere, Ionosphere, Mesosphere Energetics and Dynamics (TIMED) Global Ultraviolet Imager (GUVI; Christensen et al., 2003) and the Defense Meteorological Satellite Program (DMSP) F16 and F18 Special Sensor Ultraviolet Spectrographic Imager (SSUSI; Paxton et al., 2002). Section 2.1 reviews information on these instruments given in Knight et al. (2018) and also gives extra information relevant for proton auroral emissions. Section 2.2 gives a very brief summary of Digisonde (Reinisch, 1996; Reinisch et al., 2009) ionosonde data sources and interpretation methods, which are described in detail in Knight et al. (2018). Ionogram analysis for this work was performed by the University of Massachusetts, Lowell, Space Science Laboratory. Coincident FUV images, ionograms, and extracted parameters are provided at the following website created for this project: http://www.cpi.com/projects/fuvi.html (last access: 18 January 2021). Section 3 describes the expected effects, given the abovementioned B3C model and FUV/in situ comparison results, of proton precipitation on the accuracy of auroral FUV remote sensing algorithms that derive $\mathrm{E}$ region parameters in terms of LBH emission, assuming pure electron precipitation.

Then Sect. 4.1 presents the actual statistical effects of proton aurora found in the coincident FUV and ionosonde NmE observations. Surprisingly, no statistical effect on the accuracy of FUV-derived NmE is found. As described in Knight et al. (2018), strong statistical agreement was found between FUV-derived and ionosonde-observed auroral $\mathrm{NmE}$. In the former, $\mathrm{NmE}$ is derived from precipitating particle characteristics inferred from LBH emission. In the latter, NmE is inferred from the maximum radio frequency at which signal echoes are received by ionosondes (roughly speaking). Since both observation methods give information on auroral NmE (albeit from using very different methods), and since a strong statistical relationship was found between the two types of NmE observations in Knight et al. (2018), it is to be expected that if proton precipitation biases FUV-derived $\mathrm{NmE}$ then such an effect could be detected statistically in the FUV-ionosonde comparisons. In fact, we quantify the ex- pected statistical effect using a statistical simulation in the appendix. Possible explanations for the unexpected lack of a proton auroral bias in FUV-derived $\mathrm{NmE}$ are considered in Sect. 4.2.

While good statistical agreement between the two types of auroral $\mathrm{E}$ region observations was reported for $\mathrm{NmE}$ in Knight et al. (2018), poor agreement was reported for $\mathrm{hmE}$ (the height at which the maximum $\mathrm{E}$ region electron density occurs). Based on statistical analysis (omitted here), it is clear that this lack of agreement is unrelated to effects of proton precipitation. The reader is referred to Knight et al. (2018) for a discussion of the possible reasons for the lack of agreement in hmE. Here, we do not include statistical analysis of effect of proton aurora on the level of agreement in $\mathrm{hmE}$, since it appears that there are other factors involved that prevent such a comparison from giving meaningful results on the effect of proton precipitation on FUV-derived hmE accuracy.

\section{Data and methods}

\subsection{Auroral FUV}

This subsection will mostly be a review of Sect. 2 of Knight et al. (2018), along with some additional information specific to the Ly- $\alpha$ line, i.e., HI $121.6 \mathrm{~nm}$, which is produced by proton aurora. For additional details, the reader is referred to Knight et al. (2018). TIMED is in an orbit that precesses $\sim 0.2 \mathrm{~h}$ of local time per day, while F16 and F18 are in Sun-synchronous orbits. Each of the three satellites passes through the northern (as well as the southern) highlatitude region once every $\sim 100 \mathrm{~min}$. The three FUV instruments record images of radiances in five FUV channels, referred to as 1216, 1304, 1356, LBH short (LBHS), and LBH long (LBHL), with the first three corresponding to the HI $121.6 \mathrm{~nm}$, OI $130.4 \mathrm{~nm}$, OI $135.6 \mathrm{~nm}$ lines, and the last two corresponding to two wavelength intervals in which $\mathrm{N}_{2}$ $\mathrm{LBH}$ radiance predominates. Their wavelength intervals are approximately [140 nm; $152 \mathrm{~nm}]$ and $[165 \mathrm{~nm} ; 180 \mathrm{~nm}]$, respectively, except for early F16 SSUSI LBHS, which was a bit different, as described in Knight et al. (2018). When we use the term 1216 without wavelength units, it is meant as an instrument channel name and not as a scientific term for the HI $121.6 \mathrm{~nm}$ feature.

LBHS and LBHL responsivities per pixel for the three instruments are given in Table 1 of Knight et al. (2018). The GUVI, F16 SSUSI, and F18 SSUSI 1216 responsivities in counts per kilorayleigh per pixel, are 1.3, 3.7, and 2.1, respectively. (This applies to calibration versions C, E, and B, respectively, as in Table 1 of Knight et al., 2018.) We extract radiance values for this study by averaging over pixels within a $30 \mathrm{~km}$ radius of the location of the coincident ground station for an overpass. At the nadir, there are $\sim 57.5$ pixels per averaging area for GUVI and $\sim 28.5$ for SSUSI. Only half of 
the SSUSI 1216 pixel values are downlinked by F16 and F18. The missing pixel values are provided in Level 1B (L1B) files by means of an estimate in terms of surrounding pixel values. This gives effective 1216 responsivities of $0.075,0.053$, and 0.030 counts per $\mathrm{R}$ per averaging area for GUVI, F16 SSUSI, and F18 SSUSI, respectively.

A total of 2047 qualifying overpasses by the three satellites over the four ground stations were found for the time period covered by our study, i.e., from 2002 through 2014. For us, a qualifying overpass is one for which the solar zenith angle (SZA) is at least $100^{\circ}, \mathrm{LBHL}$ is at least $200 \mathrm{R}$, the FUV instrument look angle is less than $40^{\circ}$, and there are no errors in the FUV data. For the analysis described here, there was an additional condition for F16, which was that F16 SSUSI LBHL should be at least $300 \mathrm{R}$. This condition was added because of the poorer agreement between F16 SSUSI and ionosonde observations described in Knight et al. (2018) Sect. 4.1. This work required the subtraction of geocorona from 1216 radiances to give an estimate of the auroral 1216 signal. We developed an algorithm for fitting geocorona to 1216 radiance images, but the algorithm could not be applied to all overpasses (e.g., because of missing L1B data). The overpasses for which geocorona could not be estimated are excluded from the analysis described here. Geocorona removal increases the relative uncertainty in the remaining signal as explained in, for example, Knight et al. (2008), paragraph 35 .

This study uses exactly the same method for deriving $\mathrm{NmE}$ and hmE from auroral FUV as is described in Knight et al. (2018) Sect. 2.3. The method assumes that LBHS and LBHL values are produced by pure electron aurora with Gaussian (i.e., nearly monoenergetic) spectra. As illustrated by Knight et al. (2018) Fig. 1, NmE and hmE are estimated from LBHS and LBHL using tabulated values indexed only by the ratio LBHS/LBHL and instrument look angle. As described in Sect. 4.1, the hypothesis that proton aurora causes a bias in auroral FUV algorithms that derive NmE from $\mathrm{LBH}$ was tested by characterizing the statistical effect of auroral HI $121.6 \mathrm{~nm}$ (associated with proton precipitation) on biases between FUV-derived and ionosonde-observed NmE.

\subsection{Ionosonde}

Ionosonde observations were provided by the following four Digisondes located at magnetic latitudes between 60 and $70^{\circ}$ : Gakona (Alaska, USA), Goose Bay (Canada), Norilsk (Russia), and Troms $\emptyset$ (Norway). All ionogram-derived data values for this study were provided by the University of Massachusetts, Lowell, Space Science Laboratory. Our method for extracting auroral ionospheric E region parameters from ground-based ionosonde observations is described in detail in Sect. 3 of Knight et al. (2018). The ionosondes record ionograms once every $\sim 15 \mathrm{~min}$, generally, and for every overpass there will be two ionograms to be considered, i.e., immediately before and after the exact time of coincidence.

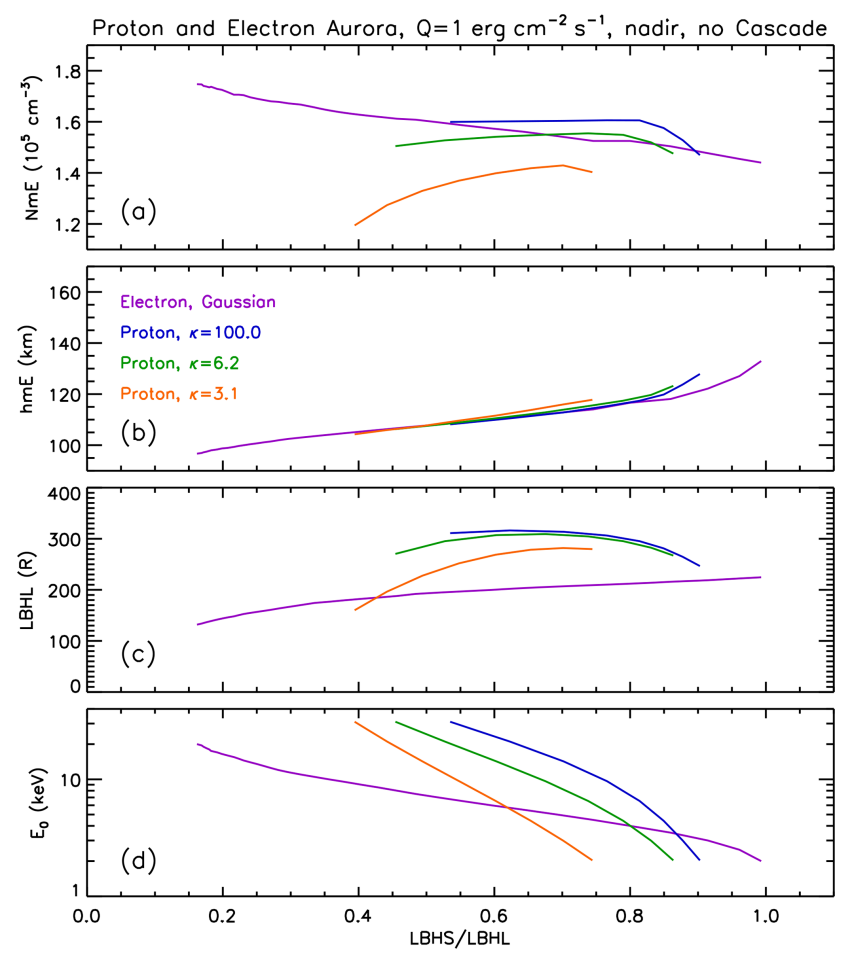

Figure 1. Model-generated auroral $\mathrm{NmE}$ (a), hmE (b), LBHL (c), and $\mathrm{E}_{0}$ (d) plotted versus LBHS/LBHL for pure electron aurora with a Gaussian spectral shape and pure proton aurora with a kappa function shape for three different $\kappa$ values $(100,6.2$, and 3.1). Only values for nadir viewing are shown. LBH emissions do not include cascade contributions, as explained in the text.

Auroral E region parameters could be extracted from one or both of the ionograms for $\sim 55 \%$ of the qualifying overpasses, and in $\sim 30 \%$ of these cases, auroral E region parameters could not be extracted for exactly one of the two ionograms (meaning $\sim 15 \%$ for the pre-coincidence ionogram and $\sim 15 \%$ for the post-coincidence ionogram).

\section{Expected effect of proton precipitation}

Proton precipitation is expected to make auroral FUV remote sensing algorithms based only on LBH (and assuming pure electron precipitation) inaccurate because proton and electron precipitation produce $\mathrm{LBH}$ emission and $\mathrm{E}$ region ionization in different quantities per unit of precipitating energy flux. Figure 1 illustrates some of these expected differences. The values shown in the figure were generated with the B3C model, based on the same assumptions as in Sect. 2.3 of Knight et al. (2018), except for one difference, which is that, in Fig. 1, the contribution to LBH of cascade from the $\mathrm{N}_{2}$ (a') and $\mathrm{N}_{2}(\mathrm{w})$ states to the $\mathrm{N}_{2}$ (a) state is not included. Instead, all of the LBH cross sections (including electron, proton, and hydrogen atom impact) are as described in Knight et al. (2012). The reason for this is that we do not 
have cross sections for proton and hydrogen atom impact that describe cascade at this time, and the inclusion of cascade for electrons, but not protons and hydrogen atoms, would not be self-consistent.

Figure 1 shows $\mathrm{B} 3 \mathrm{C}$ results based on nadir viewing for Gaussian electron spectra, in addition to three proton flux kappa function (e.g., Knight et al., 2012) spectra for $\kappa$ values of 3.1, 6.2, and 100. The kappa function becomes wider (as a function of energy) for smaller $\kappa$ values and approaches a Maxwellian shape as $\kappa \rightarrow \infty$. The three $\kappa$ values used in the figure are representative of the range of proton spectral shapes that have been observed (e.g., Coumans et al., 2002). The incident flux spectra all have spectrally integrated energy flux (denoted by $Q$ ) equal to $1 \mathrm{erg} \mathrm{cm}^{-2} \mathrm{~s}^{-1}$. $E_{0}$ values outside of the ranges shown for the three proton auroral $\kappa$ values do not occur generally.

Mixed proton and electron aurora is actually more common than pure proton aurora (see, e.g., Knight et al., 2012; Fig. 4), but Fig. 1 at least gives an idea of what is expected from the two different types of aurora. LBH radiances resulting from simultaneous electron and proton precipitation are simply the linear combination of the radiances that would result from the two types of precipitation separately. Also, as discussed in Sect. 2.3 of Knight et al. (2018), under the assumption of local equilibrium between $\mathrm{E}$ region ionization and recombination processes, electron density is approximately proportional to the square root of the sum of squares of electron densities that would result from two different sources of ionization (i.e., electron and proton aurora, in this case). For further explanation, the reader is referred to Zhang et al. (2010) Eqs. (1)-(5), which deal with the conceptually similar situation in which the two sources of ionization are electron precipitation and solar photo-ionization. In fact, since auroral ionization rates change linearly with changes in incident precipitating particle flux (e.g., Basu et al., 1987), it follows in the same way from the assumption of local equilibrium that, for a given particle type and incident particle flux spectral shape, E region electron density at a given altitude will be approximately proportional to the square root of $Q$ (i.e., total incident energy flux) for that particle type.

Figure 1a shows that, in near-Maxwellian cases, proton aurora produces $\mathrm{NmE}$ values that are similar to those produced by Gaussian electron spectra for the same LBHS / LBHL ratio, while proton auroral $\mathrm{NmE}$ decreases for wider proton spectra with the same energy flux. The hmE values as functions of LBHS/LBHL are similar for all four cases shown in Fig. 1b. For the two narrower proton spectra, LBHL values are $\sim 50 \%$ (that is, a factor of $\sim 1.5$ ) higher than for electron spectra with the same precipitating energy flux and LBHS/LBHL values.

Taken in combination, these model results imply that the auroral FUV algorithm that assumes pure electron flux will give $\mathrm{NmE}$ values that are too high by a factor of $\sim \sqrt{1.5}=$ 1.22 (taking the square root of 1.5, the typical ratio of LBHL emission efficiencies just stated) for pure proton flux spectra when the proton spectra are narrow, that is, $\kappa \geq \sim 6.2$. The situation is more complicated for smaller $\kappa$ (e.g., $\kappa=\sim 3.1$, since these differ with the narrower spectra in both $\mathrm{NmE}$ and LBHL, but it can be seen that, in general, there will still be an auroral FUV algorithm bias in the vicinity of 1.22 or greater for the wider type. To illustrate this, consider the case in which $\kappa=3.1$ and LBHS / LBHL $=0.42$ (where the orange and purple lines cross in Fig. 1c). The proton and electron LBHL yields are the same in this case, but it can be seen in Fig. 1a that, at LBHS / LBHL $=0.42$, the NmE value for the purple curve is $\sim 1.3$ times that of the orange curve, so the FUV-based remote sensing algorithm will overestimate $\mathrm{NmE}$ by a factor of $\sim 1.3$ (noting that $1.3>1.22$ ) in this case if the emission is produced by proton aurora with $\kappa=3.1$.

The above discussion gives a general idea of why the auroral FUV remote sensing algorithm for $\mathrm{NmE}$ is expected to be biased by a factor of at least 1.22 for pure proton aurora, but in order to predict the bias for ensembles of observations, it is necessary to consider mixed proton and electron aurora with varying spectral shapes. In Sect. 4.1, a statistical approach will be applied to ensembles of (nearly) coincident FUV and ionosonde observations. The results of Sect. 4.1 will be evaluated in the Appendix in terms of a statistical simulation based on actual in situ ion (treated as proton) and electron flux observations, including realistic distributions of spectral shapes and electron and proton energy fluxes.

We include model-predicted hmE values in Fig. $1 \mathrm{~b}$ for the sake of completeness, although comparisons of FUV-derived and ionosonde-observed $\mathrm{hmE}$ are not included in this work for the reasons mentioned in Sect. 1. It can be inferred from Fig. $1 \mathrm{~b}$ that there should be little bias in derived hmE for pure proton aurora.

The proton auroral LBH yields on which Fig. 1 is based are the same as those described in Knight et al. (2008, 2012), and a comparison with electron and proton auroral emissions reported for other models (e.g., by Hubert et al., 2001) was made in Knight et al. (2008) Sect. 5.2. The proton auroral hmE and $\mathrm{NmE}$ values for the blue curves (i.e., near Maxwellian) shown in Fig. 1 may be compared with the electron density profiles shown in Galand and Richmond (2001) Fig. 1b. They give electron density for incident proton energy flux equal to $1 \mathrm{~mW} \mathrm{~m}^{-2}$, which is the same as $1 \mathrm{erg} \mathrm{cm}^{-2} \mathrm{~s}^{-1}$. Their NmE values are all $\sim 1.8 \times 10^{5} \mathrm{~cm}^{-3}$ for Maxwellian proton flux spectra, with $\mathrm{E}_{0}$ values from 1 to $20 \mathrm{keV}$, and their hmE values go from $\sim 130 \mathrm{~km}$ at $\mathrm{E}_{0}=1 \mathrm{keV}$ to $\sim 116 \mathrm{~km}$ at $\mathrm{E}_{0}=20 \mathrm{keV}$. Their NmE values are $\sim 12.5 \%$ larger than our values of $\sim 1.6 \times 10^{5} \mathrm{~cm}^{-3}$ shown in Fig. 1a, and their hmE values are similar to our values shown in Fig. 1b. Some comparisons were made between in situ ion (treated as proton) flux data and E region densities predicted by particle transport models for proton aurora in Basu et al. (1987) Fig. 8, but the electron densities shown there seem puzzlingly low.

While it was already apparent from model results that proton precipitation would cause inaccuracies in auroral remote 
sensing methods based on LBH emissions (and assuming pure electron precipitation), it was implied by some studies comparing coincident auroral LBH observations and in situ electron and ion (treated as proton) flux data that the inaccuracies would be much worse than was predicted by models. These studies all involve SSUSI and Special Sensor J5 (SSJ5) observations made from aboard the same satellites, as described in Aerospace et al. $(2006,2011)$ and Knight et al. (2008, 2012). (Also, Correira et al., 2011, revised some results from Knight et al., 2008.) These studies all concluded that $\mathrm{B} 3 \mathrm{C}$ and other auroral transport and emission models were underestimating the efficiency of proton aurora (per unit energy flux) in producing LBH emission. The most likely explanation for the apparent underestimate was thought to be inaccurate LBH emission cross sections for proton and hydrogen impact, although other factors, which will be discussed shortly, could be involved.

SSJ5 is an in situ particle flux detector that observes precipitating electron and ion (treated as proton) fluxes in orbit at the location of the instrument. Additional details about the SSJ5 instrument may be found in Knight et al. (2008), Emery et al. (2008), and Aerospace et al. (2006, 2011). Since SSJ5 does not observe fluxes at energies above $30 \mathrm{keV}$, and since most of the auroral proton flux is often at energies above $30 \mathrm{keV}$, it was necessary to use proton extrapolation methods in the above-listed comparisons. The following two types of extrapolation methods were involved: an earlier climatological method (Aerospace et al., 2006; Knight et al., 2008; Correira et al., 2011) and a later non-climatological method (Aerospace et al., 2011) and Knight et al. (2012). Some of the model assumptions underlying the later non-climatological extrapolation method will be considered in Sect. 4.2.

In the comparisons just listed, monoenergetic emission feature yield curves derived from B3C model results (see Knight et al., 2012; Fig. 1) were used to derive radiances from SSJ5 flux observations by integrating the products of the monoenergetic yield curves with the SSJ5 fluxes. (See Eq. 1 of Knight et al., 2012 and the surrounding text for additional information on this method.) The radiance values obtained from SSJ5 fluxes were then compared with coincident radiances obtained by averaging SSUSI L1B pixels over coincident areas. These values will be referred here to as $\mathrm{J} 5_{\mathrm{e}}$ (LBHS), $\mathrm{J} 5_{\mathrm{p}}$ (LBHS), and SSUSI(LBHS), and likewise for LBHL. Here, the e and p subscripts refer to electron and ion (treated as proton) flux. Extrapolation above $30 \mathrm{keV}$ is included in the derivation of radiances for proton fluxes. The statistical SSUSI / SSJ5 ratios $\mathrm{f}_{\mathrm{e}}^{\mathrm{LBHS}}$ and $\mathrm{f}_{\mathrm{p}}^{\mathrm{LBHS}}$ are values fitted to the overdetermined equation, for example, as follows:

$\operatorname{SSUSI}($ LBHS $) \approx \mathrm{f}_{\mathrm{e}}^{\mathrm{LBHS}} \mathrm{J}_{\mathrm{e}}(\mathrm{LBHS})+\mathrm{f}_{\mathrm{p}}^{\mathrm{LBHS}} \mathrm{J} 5_{\mathrm{p}}(\mathrm{LBHS})$,

(and similarly for LBHL) for an ensemble of SSUSI-SSJ5 coincidences. See Knight et al. (2008, 2012) for a description of the fitting method. The SSUSI / SSJ5 statistical ratios describe the level of agreement between SSUSI, SSJ5, and the model (B3C in our case) in terms of two multiplicative factors, which represent the combined effect of model and instrument calibration errors (if any). In fact, the systematic errors may not be purely multiplicative, but it is reasonable to assume that they are multiplicative as a first-order approximation. Under ideal conditions, with exact models, perfect coincidences, perfect extrapolation, no noise, and no instrument calibration errors, one would expect that $\mathrm{f}_{\mathrm{e}}^{\mathrm{LBHS}}$ and $\mathrm{f}_{\mathrm{p}}^{\mathrm{LBHS}}$ would both be unity and that the left side of Eq. (1) would equal the right side for every coincident observation.

Define $\mathrm{f}_{\mathrm{p} / \mathrm{e}}^{\mathrm{LBHS}}=\mathrm{f}_{\mathrm{p}}^{\mathrm{LBHS}} / \mathrm{f}_{\mathrm{e}}^{\mathrm{LBHS}}$ and $\mathrm{f}_{\mathrm{p} / \mathrm{e}}^{\mathrm{LBHL}}=\mathrm{f}_{\mathrm{p}}^{\mathrm{LBHL}} / \mathrm{f}_{\mathrm{e}}^{\mathrm{LBHL}}$. These ratios of ratios are more useful than individual statistical SSUSI / SSJ5 ratios for describing model underestimates of proton LBH emission efficiency, since SSUSI calibration errors (if any) tend cancel out in the ratios. In the nonclimatological extrapolation method, moreover, it is assumed that $\mathrm{f}_{\mathrm{p} / \mathrm{e}}^{\mathrm{LBHS}}=\mathrm{f}_{\mathrm{p} / \mathrm{e}}^{\mathrm{LBHL}}$. (See Knight et al., 2012 for the reasoning behind this assumption.) Under this assumption, let $\mathrm{f}_{\mathrm{p} / \mathrm{e}}^{\mathrm{LBH}}$ denote the value of the two ratios, which will be referred to as a proton/electron model LBH bias. Practically speaking, any estimate of proton/electron model LBH bias from actual observations is affected by in situ flux detector bias, proton extrapolation error, and other issues discussed in Knight et al. $(2008,2012)$, but it is still convenient for our purposes to be able to think of it as a model bias for which the estimation methods themselves, in practice, can be biased.

Proton/electron model LBH biases of 3.00 (Knight et al., 2012; Table 4), 2.31 (Aerospace et al., 2011; Figs. 7.1-14), and 1.84 (Gelinas and Hecht, 2016) were found in F16, F18, and F19 (respectively) SSUSI-SSJ5 comparisons. (The differences between these values for F16, F18, and F19 are accounted for to some extent by minor changes in the analysis method, which are explained in Gelinas and Hecht (2016). These changes have to do with refinements in how the SSUSI instrument response to spectral radiance is modeled.) For the sake of discussion, we will say that the proton/electron model LBH bias implied by these results in combination is $\mathrm{f}_{\mathrm{p} / \mathrm{e}}^{\mathrm{LBH}}=\sim 2$. Since the B3C model already predicts that proton aurora is a factor of $\sim 1.5$ more efficient in producing $\mathrm{LBH}$ than electron aurora (as described earlier in this section), $\mathrm{f}_{\mathrm{p} / \mathrm{e}}^{\mathrm{LBH}}=2$ implies that proton aurora is actually $2 \times 1.5=3$ times as efficient as electron aurora in producing LBH aurora. Since the auroral FUV remote sensing algorithm (see Knight et al., 2018; Eq. 2) sets NmE in proportion to the square root of LBHL (which is justified by the above observations on electron density being approximately proportional to the square root of $Q$ ), it is implied that the algorithm should give $\mathrm{NmE}$ values that are a factor of approximately $\sqrt{3}=1.73$ too high for pure proton aurora.

The SSUSI-SSJ5 comparison method described above is designed in such a way to allow SSUSI calibration errors (if any) to drop out, but it is still sensitive to SSJ5 calibration errors (if any). It is especially sensitive to SSJ5 ion flux cal- 
ibration errors at the two highest energy channels, i.e., $\sim 20$ and $30 \mathrm{keV}$.

\section{FUV-ionosonde proton analysis}

\subsection{Statistical results for $\mathrm{NmE}$}

As described in Sect. 3, based on model results, it is expected that FUV-derived auroral NmE (i.e., derived under the assumption of pure electron aurora) will be too high for pure proton aurora by a factor of $\sim 1.22$, and based on SSUSISSJ5 comparisons, it is expected that the proton bias factor will have a much larger value of $\sim 1.73$. It turns out, however, that our FUV-ionosonde comparisons indicate that there is no proton auroral bias in FUV-derived NmE.

Let the ionosonde-coincident radiances be denoted by the instrument name, followed by a subscript indexing the coincidence number, followed by the FUV channel in parentheses. For the 1216 channel, bc will be added to indicate that the radiances have been corrected for geocoronal background. For example, $\operatorname{GUVI}_{i}(1216$; bc) is the ith coincident background-corrected GUVI 1216 value, and F16-SSUSI $i$ (LBHS) is the $i$ th coincident F16-SSUSI LBHS value. When the whole set of coincident values for one instrument is being represented, the index subscript will be omitted. The exact relative contribution of precipitating proton energy flux to the total incident proton and electron energy flux (or to any of the channel radiances) cannot be determined from the radiances, but a variable can be defined in terms of the radiances that at least tends to increase or decrease with the relative level of proton energy flux. This proton-indicating variable (PIV) will be denoted by $\mathrm{GUVI}_{i}$ (PIV), F16-SSUSI $i$ (PIV), and F18-SSUSI $i$ (PIV) and is given as follows:

$$
\begin{aligned}
& \operatorname{GUVI}_{i}(\mathrm{PIV})= \\
& \frac{\frac{\mathrm{GUVI}_{i}(1216, \mathrm{bc})}{\operatorname{median}(\mathrm{GUVI}(1216, \mathrm{bc}))}}{\frac{\mathrm{GUVI}_{i}(1216, \mathrm{bc})}{\operatorname{median}(\mathrm{GUVI}(1216, \mathrm{bc}))}+\frac{\mathrm{GUVI}_{i}(\mathrm{LBHL})}{\operatorname{median}(\mathrm{GUVI}(\mathrm{LBHL}))}},
\end{aligned}
$$

for GUVI and likewise for the other two instruments. For nonnegative radiances, this will take on values between zero and one. The purpose of normalizing by the medians is to reduce the effects of possible calibration differences between the instruments so that the proton-indicating variable takes on the same approximate range of values for all three instruments. It also turns out that the normalization causes the PIVs to have a median value of approximately 0.5 for all three instruments, which simply means that the two conditions are as follows:

$$
\begin{aligned}
& \frac{\operatorname{GUVI}_{i}(\mathrm{LBHL})}{\operatorname{median}(\mathrm{GUVI}(\mathrm{LBHL}))}>\frac{\mathrm{GUVI}_{i}(1216, \mathrm{bc})}{\operatorname{median}(\mathrm{GUVI}(1216, \mathrm{bc}))}, \\
& \frac{\mathrm{GUVI}_{i}(\mathrm{LBHL})}{\operatorname{median}(\mathrm{GUVI}(\mathrm{LBHL}))}<\frac{\mathrm{GUVI}_{i}(1216, \mathrm{bc})}{\operatorname{median}(\mathrm{GUVI}(1216, \mathrm{bc}))},
\end{aligned}
$$

and are approximately equally likely - and likewise for the other two instruments. There are a number of reasons why the PIV does not exactly determine the relative level of proton precipitation. As can be seen in Fig. 1 of Knight et al. (2012), the Ly- $\alpha$ yield varies with precipitating particle energy. Also, electron auroral NI $120.0 \mathrm{~nm}$ emission contributes to the instrument response in the Ly- $\alpha$ channel, as discussed in Knight et al. (2008, 2012). Regardless, it is clear that the PIV must be statistically associated with proton aurora.

If there were a bias in FUV-derived NmE associated with proton aurora, then it would be expected that the PIV would provide some extra information so that, in combination with FUV-derived NmE, it would allow a better prediction of ionosonde-observed NmE. In order to determine whether this is the case, we first use regression to obtain an estimate of ionosonde-observed $\mathrm{NmE}$ in terms of FUV-derived NmE and then study the statistical relationship between the PIVs and the residuals.

We now introduce some additional notation. The FUV-derived $\mathrm{NmE}$ values are denoted by, for example, $\mathrm{GUVI}_{i}(\mathrm{NmE}, \mathrm{F})$, where F stands for FUV, and the coincident ionosonde-observed values are denoted by, for example, $\mathrm{GUVI}_{i}(\mathrm{NmE}, \mathrm{I}$, pre), GUVI $i(\mathrm{NmE}, \mathrm{I}$, post), where I stands for ionosonde and pre and post indicate the ionosonde observations immediately before and after (respectively) the time of coincidence. (It may seem counter-intuitive to label ionosonde observations according to coincident FUV instruments, but this approach makes sense here because our transformations of data values are specific to FUV instruments and not ground stations.)

Our regression method is as follows. To reduce the effect of outliers, we convert to log space and use least absolute deviation regression to fit coefficients, e.g., $\operatorname{GUVI}(\alpha$, pre $)$, $\operatorname{GUVI}(\beta$, pre $)$, to the data as follows:

$$
\begin{aligned}
& \ln \left(\operatorname{GUVI}_{i}(\mathrm{NmE}, \mathrm{I}, \text { pre })\right) \approx \operatorname{GUVI}(\alpha, \text { pre }) \\
& +\operatorname{GUVI}(\beta, \text { pre }) \ln \left(\mathrm{GUVI}_{i}(\mathrm{NmE}, \mathrm{F})\right),
\end{aligned}
$$

and likewise for post-coincidence ionograms and the other two FUV instruments. These fitted lines are illustrated by Fig. 2, which shows ionosonde-observed $\mathrm{NmE}$ ( $y$ axis) plotted versus FUV-derived NmE values ( $x$ axis) with the fitted lines. This figure is similar to Figs. 6 and 7 from Knight et al. (2018), with the following differences: (1) there are fewer F16 points because a $300 \mathrm{R}$ threshold is used for F16, (2) the $x$ and $y$ axes have been reversed, (3) this figure shows fitted lines and (4) a few GUVI and F18 points are excluded here because of extra conditions described in Sect. 2.1. 

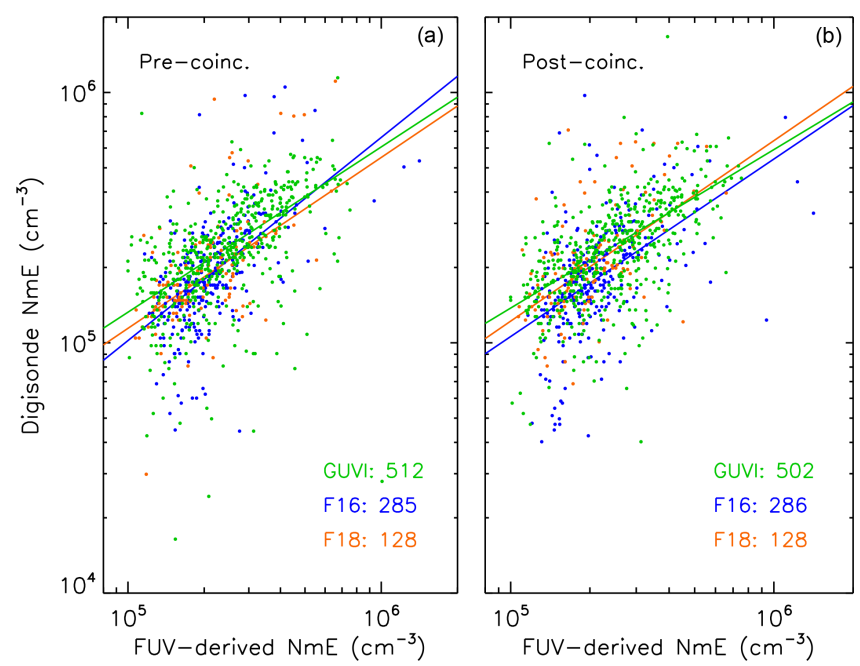

Figure 2. Ionosonde-observed $\mathrm{NmE}$ ( $y$ axis) plotted versus FUV-derived NmE for pre-coincidence (a) and post-coincidence Digisonde observations. Color-coded lines for the three satellites have been fitted in log space to the $x$ and $y$ values using least absolute deviations, as described in the text, for the purpose of determining residuals, as described in the text.

The reader is referred to Knight et al. (2018) for a discussion of the consistency between the FUV and ionosonde observations. The exact values of the parameters of the fitted lines in Fig. 2 are not of direct interest here. The purpose here is to determine whether the PIV adds extra information (for predicting ionosonde-derived $\mathrm{NmE}$ ) that is not already provided by FUV-derived NmE. At a basic, conceptual level, the approach to be used here is similar to the approach of comparing reduced and full models described in Rencher and Schaalje (2008; Sects. 7.10 and 8.2). Our approach, to be described next, relies on a statistical simulation to establish a result rather than a formal mathematical method, such as the $F$ test of Rencher and Schaalje (2008; Sect. 8.2).

We use the term residual to refer to the ratio of ionosondeobserved NmE to the value estimated from FUV-derived $\mathrm{NmE}$ by applying the exponential function to the right side of Eq. (5). The notation, for example, $\mathrm{GUVI}_{i}(\mathrm{Res}(\mathrm{NmE})$, pre) will denote the residual value given by the following:

$\mathrm{GUVI}_{i}(\operatorname{Res}(\mathrm{NmE}), \mathrm{pre})=$

$\frac{\mathrm{GUVI}_{i}(\mathrm{NmE}, \mathrm{I}, \text { pre })}{\exp \left(\mathrm{GUVI}(\alpha, \text { pre })+\mathrm{GUVI}(\beta, \text { pre }) \ln \left(\mathrm{GUVI}_{i}(\mathrm{NmE}, \mathrm{F})\right)\right)}$.

This generalized type of residual, which will sometimes be referred to simply as $\operatorname{Res}(\mathrm{NmE})$, is dimensionless, since the right side of Eq. (6) has a ratio of NmE values. Although the term residuals usually refers to differences and not ratios, note that a ratio can be interpreted as a difference in logarithmic space.

When data values for all three FUV instruments are combined, they will be referred to with the same notation as before, except with the instrument abbreviation replaced by
COMB. The calculations of residuals and PIVs are still instrument specific and are performed prior to combining the derived values. Let COMB (Res(NmE), PIV $<0.5$, pre) and COMB (Res(NmE), PIV $\geq 0.5$, pre) be the subsets of COMB (Res(NmE), pre) for which PIV is or less than 0.5 and greater than or equal to 0.5 , respectively. These will be referred to as below and above sets. Similar definitions can be made for the post-coincidence ionograms and the individual FUV instruments. The statistical effect of proton aurora on $\operatorname{Res}(\mathrm{NmE})$ will now be described in terms of the ratio of medians as follows:

$\operatorname{COMB}(\mathrm{BAR}$, pre $)=$

$$
\frac{\text { median }(\mathrm{COMB}(\operatorname{Res}(\mathrm{NmE}), \text { PIV }<0.5, \text { pre }))}{\text { median }(\mathrm{COMB}(\operatorname{Res}(\mathrm{NmE}), \text { PIV } \geq 0.5, \text { pre }))}
$$

for pre-coincidence $\operatorname{Res}(\mathrm{NmE})$, where $\mathrm{BAR}$ stands for below-to-above ratio. A similar formula for COMB(BAR,post) is obtained by changing "pre" to "post" in Eq. (7). The BAR quantity will be referred to as a statistic because it is an aggregate property of the sets of values being compared.

Figure 3 shows PIV ( $x$ axis) and $\operatorname{Res}(\mathrm{NmE})$ ( $y$ axis) values derived from FUV-ionosonde coincidences for precoincidence (upper panel) and post-coincidence (lower panel) ionograms. The numbers of points included in COMB (Res $(\mathrm{NmE}), \mathrm{PIV}<0.5$, pre), etc., are shown in the lower left and right corners of both panels. The geocorona removal method (see Sect. 2.1) results in some $\operatorname{COMB}(1216, b c)$ values that are less than zero, which is why negative PIV values occur. PIV values below -0.25 are set to -0.25 . The below and above medians in the numerator and denominator (respectively) of Eq. (7) are plotted as gray horizontal solid lines, and it can be seen they are all close to unity. In fact, all four medians are within 0.015 of unity, and the BARs are COMB (BAR, pre) $=1.012$ and COMB $($ BAR, post $)=0.974$. Since the two BAR statistics are on opposite sides of unity, it is immediately evident that there is no indication of a bias associated with proton aurora. BARs for the individual instruments (not shown) were also computed, and they are near unity as well.

The significance of the medians of the four sets, i.e., $\quad \mathrm{COMB}(\operatorname{Res}(\mathrm{NmE}), \mathrm{PIV}<0.5$, pre $)$, COMB (Res(NmE), PIV $\geq 0.5$, pre), COMB (Res(NmE), PIV < 0.5, post), and COMB (Res(NmE), PIV $\geq 0.5$, post), can be understood as follows. Van der Vaart (1998; pp. 54-55) states that the sample median of a distribution is asymptotically normal (letting the sample size $n$ tend to infinity), with an asymptotic variance (i.e., the limit as $n \rightarrow \infty$ of the variance multiplied by $n$ ) equal to $\left(2 f\left(\theta_{0}\right)\right)^{-2}$, where $f$ is the probability density function of the underlying distribution, and $\theta_{0}$ is the median of the distribution. Now we convert to log space by taking the natural logarithms of all of the Res(NmE) values. We let the null hypothesis be that all of the four sets are sampled from distributions with medians 

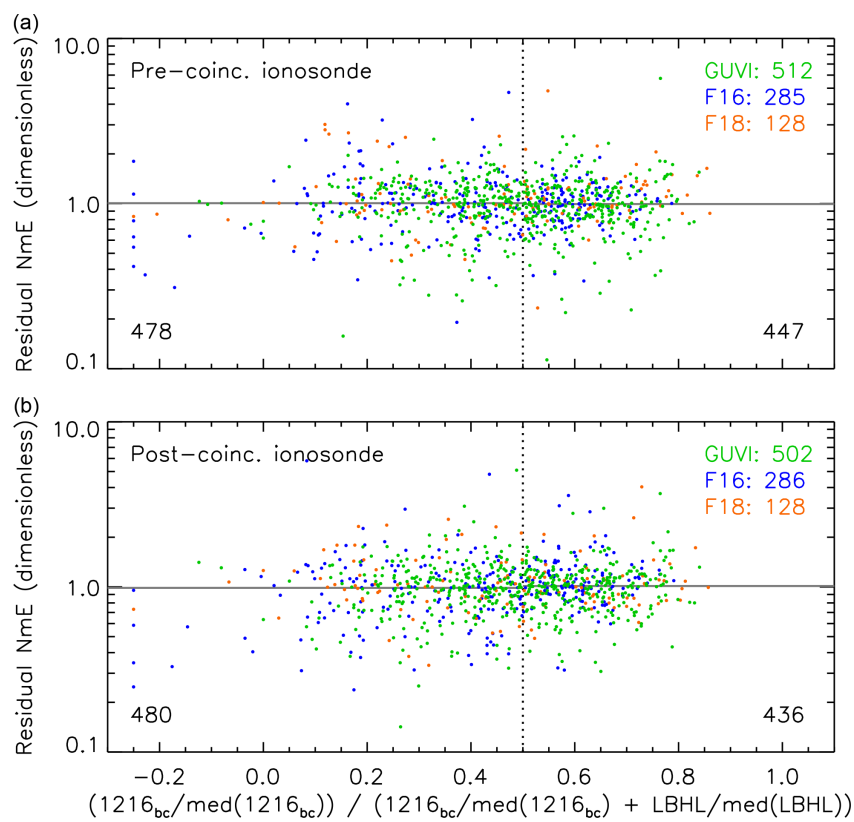

Figure 3. Residual NmE ( $y$ axis; as described in the text) plotted versus the ratio of background-corrected 1216 to the sum of background-corrected 1216 and LBHL, where the radiances are normalized by their medians. The upper and lower panels show results for ionosonde observations immediately before and after (respectively) the times of satellite coincidence with the ground stations. Horizontal gray lines indicate the median residual values in left and right bins on either side of the dotted vertical line at $x=0.5$. The numbers of points in the bins are displayed in the lower left and right corners of the panels. The numbers of points shown for each satellite are given in the upper right corners of the two panels.

equal to unity, which implies medians equal to zero in $\log$ space, i.e., $\theta_{0}=0$. The distribution standard deviations, denoted by $\sigma_{\mathrm{d}}$, of $\ln (\operatorname{Res}(\mathrm{NmE}))$ in all four sets are estimated from the data as $\sim 0.4$. We use a normal approximation and plug $\sigma_{\mathrm{d}}$ into the probability density function for a normal distribution to obtain $f\left(\theta_{0}\right) \approx\left(2 \sigma_{\mathrm{d}}^{2} \pi\right)^{-1 / 2}=\sim 1.00$. (It is just a coincidence that $f\left(\theta_{0}\right)$ is close to unity.) It is implied that the sample median has a standard deviation, denoted by $\sigma_{\mathrm{m}}$, approximately equal to $\left(2 f\left(\theta_{0}\right)\right)^{-1} n^{-1 / 2}$. Since $n \approx 450$, this gives $\sigma_{\mathrm{m}} \approx 0.024$. Since the medians are within 0.015 of unity, their natural logarithms are within $\sim 0.015$ of zero. Since the natural logarithms of all four medians are all well within $\pm \sigma_{\mathrm{m}}$, the null hypothesis is accepted for any confidence interval, including $\pm \sigma_{\mathrm{m}}$ in a normal distribution with standard deviation equal to $\sigma_{\mathrm{m}}$. This means that none of the four medians is significantly far from unity, and that therefore, there is no bias associated with proton aurora.

Given biases mentioned at the beginning of this section of $\sim 1.22$ (predicted by the B3C model) or $\sim$ 1.73 (predicted by earlier in situ comparison results) expected for auroral FUV-derived NmE in the presence of proton precipitation, one would expect a BAR statistic greater than unity. This is because FUV-derived NmE is expected to overestimate actual $\mathrm{NmE}$ when a significant portion of the observed LBH is produced by proton precipitation, meaning that COMB (Res $(\mathrm{NmE})$, pre) and COMB (Res (NmE), post) should tend to be lower when there is more proton precipitation, as indicated by the condition PIV $>0.5$. This leads to the following question: what is the likelihood that BAR statistics so close to unity would be obtained if the predicted FUV-derived NmE biases of $\sim 1.22$ or $\sim 1.73$ for proton aurora were correct? In the appendix, an answer will be obtained for this question using a statistical simulation incorporating synthetically generated sets of FUV and ionosonde observations. It will be shown there that the probability of obtaining a BAR statistic of 1.012 or 0.974 (see above) is essentially zero, given either of the predicted $\mathrm{NmE}$ biases just mentioned. Given the B3C results described in Sect. 3, the simulation described in the Appendix predicts a BAR statistic of $1.121 \pm 0.030$, and given the in situ comparison results, also described in Sect. 3, calling for proton auroral LBH emission yields to be increased by a factor of $\sim 2$, the simulation described in the appendix predicts a BAR statistic of $1.271 \pm 0.036$.

\subsection{Possible explanations for unexpected NmE result}

As just described in Sect. 4.1, the following BAR statistics, as defined by Eq. (7), were found for the FUVionosonde coincidences: $\mathrm{COMB}(\mathrm{BAR}, \mathrm{pre})=1.012$ and $\operatorname{COMB}(\mathrm{BAR}$, post $)=0.974$. The proximity of these values to unity means that there is essentially no statistical difference in the accuracy of the auroral FUV algorithm giving NmE between the two complementary sets with PIV $<0.5$ and PIV $\geq 0.5$, where PIV is the proton-indicating variable defined by Eq. (2). The PIV is defined in such a way as to be highly correlated with the ratio of precipitating proton energy flux to total electron and proton energy flux. This is because HI $121.6 \mathrm{~nm}$ emission is produced by proton aurora but not electron aurora. BAR values near unity mean that there is no apparent bias in the auroral FUV remote sensing algorithm giving NmE (assuming electron aurora) associated with proton precipitation, which is surprising given that auroral particle transport and emission models give LBH yields for proton aurora that are $\sim 50 \%$ higher than those for electron aurora. The simulation results described in the appendix suggest that BAR statistics in the vicinity of 1.12 should have been obtained if the $\mathrm{B} 3 \mathrm{C}$ model results were correct, and that somewhat larger BAR statistics in the vicinity of 1.27 should have been obtained if the in situ comparison results (e.g., Knight et al., 2012) calling for an increase in proton auroral LBH yields by a factor of $\sim 2$ were correct.

Broadly speaking, there are two approaches by which one can attempt to explain the unexpected finding. The first is to posit that the earlier in situ comparison results are incorrect. The second is to look for flaws in the methodology of 
the current study involving differences between the two types of observations (i.e., FUV and ionosonde). For the moment, the first approach will be considered. Within this approach, one can either attempt to attribute the discrepancy to potential model errors or attempt to identify potential flaws in the in situ comparison methodology or in the in situ data themselves. Setting aside the in situ comparison results for the moment, we infer from $\mathrm{B} 3 \mathrm{C}$ model results and a statistical simulation, just mentioned above, that BAR statistics in the vicinity of 1.12 should have been obtained as opposed to the values near unity which were actually obtained. This discrepancy could be accounted for by one or both of the following two types of inaccuracies in the $\mathrm{B} 3 \mathrm{C}$ model: either an overestimate of proton auroral $\mathrm{LBH}$ or an underestimate of $\mathrm{E}$ region ionization produced by proton aurora. These possibilities will not be considered further here, but it should be noted that similarities between proton auroral $\mathrm{LBH}$ emission and $\mathrm{E}$ region ionization predicted by $\mathrm{B} 3 \mathrm{C}$ and other auroral particle transport and emission models were described in Sect. 3.

Now we continue with the first approach to understanding the unexpected finding by attempting to identify flaws underlying the earlier in situ results. As described earlier, the in situ comparison results relied on the extrapolation of ion (treated as proton) flux above $30 \mathrm{keV}$, using a nonclimatological method described in Knight et al. (2012). As already mentioned, the extrapolation method is sensitive to SSJ5 ion (treated as proton) calibration errors in the two highest energy channels. As an example, if SSJ5 ion fluxes were $10 \%$ low at 20 and $30 \mathrm{keV}$, this would imply an extrapolation underestimate by approximately $10 \%$.

The extrapolation method is constrained by model assumptions, again as described in Knight et al. (2012). One type of assumption is the selection of the model atmosphere, which affects both the modeled emission yields and resulting atmospheric ionization (although it is the emission yields that are relevant to the extrapolation method). The model atmosphere used in the model runs on which the extrapolation method is based is the same as the one described in Sect. 2.3 of Knight et al. (2018). It is specified by a number of parameters, including the day of the year, local time, latitude, the geomagnetic Ap index, and the F10 index for solar activity. The extrapolation method gives slightly different answers, depending on which parameter values are selected, but these changes cannot account for the discrepancy between the FUV-ionosonde and FUV-in situ comparison results. For example, in Appendix C2 of Knight et al. (2012) it is described how different values of F10 (i.e., 80 and 150) can only account for $\mathrm{a} \sim 10 \%$ change in extrapolated proton flux. The effects of other possible model assumption errors have been considered in detail in Knight et al. (2008, 2012), Correira et al. (2011), and Aerospace et al. (2011), and no likely explanation for the discrepancy with the current results stands out. Moreover, we have filtered the FUV-ionosonde comparison sets by a number of different criteria (e.g., day of year, local time, latitude, Kp, and phase of solar cycle) in the hopes that this would point to some particular type of assumption error, but it did not.

One assumption involved in the proton flux extrapolation method (for the earlier in situ comparisons) that is worth reviewing in particular, however, is the assumption that the ion species responsible for ion fluxes observed by SSJ5 are only protons, as opposed to other types of ions, like $\mathrm{O}^{+}$. SSJ5 does not distinguish between different ion species. One way to test for the effect of the ion species assumption is to look for a change in the result when the comparison sets are filtered by the disturbance storm time (Dst) index, as discussed in paragraph 64 of Knight et al. (2008). We tried filtering by Dst in earlier in situ comparisons (i.e., Knight et al., 2008) and found that it did not affect the results. This particular test was not done for the current work, although we did filter by $\mathrm{Kp}$, as mentioned above, and did not find an effect. Regardless, the possibility that non-proton ion precipitation is responsible for the unexpected results, either in the earlier in situ comparisons or in the current FUV-ionosonde comparisons, merits further investigation.

Next, the other approach to explaining the unexpected finding, i.e., to look for flaws in the methodology of the current study, will be considered. There are a number of types of differences between the FUV and ionosonde observations, and both spatial and temporal non-uniformity exists in the aurora. The coincident observations are made at times offset by up to $15 \mathrm{~min}$ from each other. As described in Knight et al. (2018) Sect. 2.2, both types of observations gather information from a $30 \mathrm{~km}$ radius area over each ground station, but there are clearly differences in how each type of observation samples from that area. Nonetheless, a strong statistical association was found in Knight et al. (2018) between FUV-derived and ionosonde-observed NmE. Any attempt to dismiss the lack of a proton effect described in Sect. 4.1 as being caused by auroral non-uniformity and differences between the two types of observations must somehow account for why a strong statistical association between the two types of observations was found in Knight et al. (2018).

One might suppose that the difference between the BAR statistics near unity obtained in Sect. 4.1 and the expected value of 1.12 (see the Appendix) are not statistically significant, but the simulation in the appendix was designed in such a way as to show how the BAR statistic varies as a result of the randomness associated with counting statistics and auroral variability in time, and a BAR of $\sim 1.00$ was shown to be well outside the range of likely values.

We expected that FUV-derived NmE would be biased high relative to ionosonde-observed $\mathrm{NmE}$ in the presence of proton aurora, but this effect was not seen. In order for the expected bias to be hidden, there would have to be some difference between electron and proton aurora that affects the FUV and/or ionosonde observations in such a way that cancels out the expected bias. We have not thought of any plausible explanation involving this type of effect, but some ideas along these lines will now be discussed. 
One difference between electron and proton aurora is that proton/hydrogen horizontal beam spreading (e.g., Fang et al., 2007) occurs for the latter. While precipitating electrons follow the magnetic field lines to the emitting region, precipitating protons/ $\mathrm{H}$ atoms also move in directions perpendicular to the field lines to some extent. In the B3C model runs done for this analysis, it was assumed that there was no horizontal spreading, but there is no obvious way in which this could have led to the unexpected finding in the FUVionosonde comparisons. In the actual physical setting, horizontal spreading would affect both emission and ion production in similar ways, so one would not necessarily expect a bias between LBH emission and ion production to result.

Another difference between electron and proton aurora is that electron aurora can be either discrete or diffuse, while proton aurora can only be diffuse (Newell et al., 2009). Discrete aurora tends to be more variable, and one might hypothesize that the difference between discrete and diffuse aurora, affecting the two observation methods in different ways, is somehow hiding the expected proton biasing effect. As is well known, discrete and diffuse aurora tend to occur towards the poleward and equatorward boundaries of the auroral oval, respectively. The magnetic latitudes of the ground stations (see Knight et al. (2018); Table 3) range from 61.1 to 66.8. Filtering by magnetic latitude did not affect the BAR statistics, which casts doubt on the notion that discrete aurora is responsible for the unexpected result. A number of other tests were tried, such as filtering by magnetic local time and other geophysical parameters.

\section{Discussion and conclusion}

A large number of coincident auroral FUV and ground-based ionosonde observations were compared to determine the statistical effect of proton precipitation on the accuracy of auroral FUV algorithms that assume pure electron precipitation. Examples of B3C model-generated proton and electron auroral radiances and $\mathrm{E}$ region parameters (i.e., $\mathrm{NmE}$ and $\mathrm{hmE}$ ) were given in Sect. 3, and earlier FUV versus in situ precipitating particle flux comparison results, in which radiances are derived from particle fluxes and which rely on proton extrapolation above $30 \mathrm{keV}$, were summarized to explain why a bias in auroral FUV-derived NmE was expected in the presence of proton precipitation.

Surprisingly, no proton-associated bias in FUV-derived $\mathrm{NmE}$ was found (Sect. 4.1). A statistical simulation using synthetic data, described in the Appendix, indicates that this result would be quite unlikely, given the differences in proton and electron LBH yields described in Sect. 3, particularly if the large proton-associated bias predicted by in situ comparison results (Knight et al., 2012) were correct. In order to explain the lack of any bias for proton aurora, it would be necessary for either model-predicted proton auroral LBH yields to decrease or for model-predicted proton auroral NmE values to increase.

In light of this result, we cannot explain the large proton LBH bias predicted by in situ comparisons (e.g., Knight et al., 2012). The proton flux extrapolation method used in Knight et al. (2012) is constrained by observations and assumptions that cannot readily be modified. Possible explanations for the discrepancy were discussed in Sect. 4.2. The proton flux extrapolation method used in Knight et al. (2012) is sensitive to calibration errors in the two highest SSJ5 ion energy channels. The possible role of model assumptions involved in the extrapolation method was considered. The possible effect of non-proton ion precipitation on the in situ results merits a closer look. The combined role of auroral variability and differences between the two types of observations was also considered, but no explanation was found there. New comparisons of LBH and in situ auroral particle flux data, using proton flux observations that do not require extrapolation above $30 \mathrm{keV}$ (e.g., Polar-orbiting Operational Environmental Satellites Total Energy Detector, POES TED, and Medium Energy Proton and Electron Detector, MEPED) are called for.

The result that proton aurora does not introduce a bias in auroral FUV-derived NmE puts previous work that relied on auroral FUV-derived $\mathrm{NmE}$ on a firmer footing. This includes Zhang et al. (2010), in which auroral FUV-derived NmE is assimilated into an ionospheric model. This also applies to some extent to previous work in which auroral FUV-derived Hall and Pedersen conductances have been studied, including Aksnes et al. (2002) and Coumans et al. (2004), with the caveat that accuracy of NmE does not directly imply accuracy of conductances. Given the present result on $\mathrm{NmE}$, it appears likely that auroral FUV-derived energy flux (i.e., Q) is not severely biased by proton aurora to the extent predicted by Knight et al. (2008, 2012). Examples of previous work involving auroral FUV-derived Q include Brittnacher et al. (1997), Liou et al. (1998), Newell et al. (2001), Hubert et al. (2002), Baker et al. (2004), Zhang and Paxton (2008), and Luan et al. (2010). 


\section{Appendix A: Simulation to quantitatively evaluate hypotheses}

The FUV-ionosonde comparison results given in the Sect. 4.1 show no evidence of any bias (high or low) in LBHderived NmE associated with proton aurora, which is surprising given that $\mathrm{NmE}$ bias factors of $\sim 1.22$ and $\sim 1.73$ are predicted for pure proton aurora based on model and in situ comparison results, respectively. In this Appendix, a statistical simulation will be employed to determine the distribution of BAR statistics (see Sect. 4.1) that would be expected, given conditions similar to the ones described for the actual FUV-ionosonde comparison sets.

Our statistical simulation uses synthetic FUV-ionosonde comparisons generated from National Oceanic and Atmospheric Administration (NOAA) POES 17 TED and MEPED in situ electron and ion (treated here as proton) fluxes from 2003 and 2004 (Evans and Greer, 2004). LBHS, LBHL, and $\mathrm{NmE}$ values were derived for all of the POES observations, using the $\mathrm{B} 3 \mathrm{C}$ model with exactly the same set of model assumptions that were used to generate Fig. 1. In this section, the statistical ratio notation defined in Sect. 3 will be reused with a slightly different meaning. Here, it will refer to scaling factors applied to FUV values derived from particle fluxes using the $\mathrm{B} 3 \mathrm{C}$ model. In this section, $\mathrm{f}_{\mathrm{e}}^{\mathrm{LBHS}}=\mathrm{f}_{\mathrm{e}}^{\mathrm{LBHL}}=1$ and $\mathrm{f}_{\mathrm{p}}^{\mathrm{LBHS}}=\mathrm{f}_{\mathrm{p}}^{\mathrm{LBHL}} \equiv \mathrm{f}_{\mathrm{p}}^{\mathrm{LBH}}$ (defining a new term, i.e., $\mathrm{f}_{\mathrm{p}}^{\mathrm{LBH}}$ ). A particular value of $f_{p}^{\mathrm{LBH}}$ is set at the outset of each simulation run.

The idea of the simulation is to generate synthetic sets of coincident FUV and ionosonde observations comparable with actual coincident sets described in Sect. 4.1. Realism was sought in the simulation. Unfortunately, it would be too complicated to describe exactly how the needed realism was achieved, and some details are omitted so as to avoid overburdening the reader.

There are three FUV sensors and four ground stations. Let FS and GS stand for any particular FUV sensor and ground station, respectively. (In other words, FS could be either GUVI, F16, or F18, and GS could be either at Goose Bay, Gakona, Norilsk, or Troms $\varnothing$.) Let N(FS,GS) denote the number of coincident observations meeting the conditions described in Sect. 2 for the FUV sensor FS and ground station GS. In each run of the simulation, for each FS and GS, N(FS,GS) POES observations are randomly selected subject to the conditions that $\mathrm{NmE}>2 \times 10^{5} \mathrm{~cm}^{-3}$ and that the absolute value of the magnetic latitude of the POES satellite is within 0.1 degree of the magnetic latitude of the GS. A ground station NmE and a set of NI $120.0 \mathrm{~nm}, \mathrm{HI} 121.6 \mathrm{~nm}$, LBHS, and LBHL values are obtained from values already computed for each POES observation by multiplying by lognormal random variates generated with a $\sigma$ width parameter selected so as to be consistent with the value $\operatorname{SD}(\ln (y / x))=$ 0.44 shown in Knight et al. (2018) Table 4 column A.II. This is to represent the random changes that take place in actual $\mathrm{NmE}$, going from the time of the ground observation to the

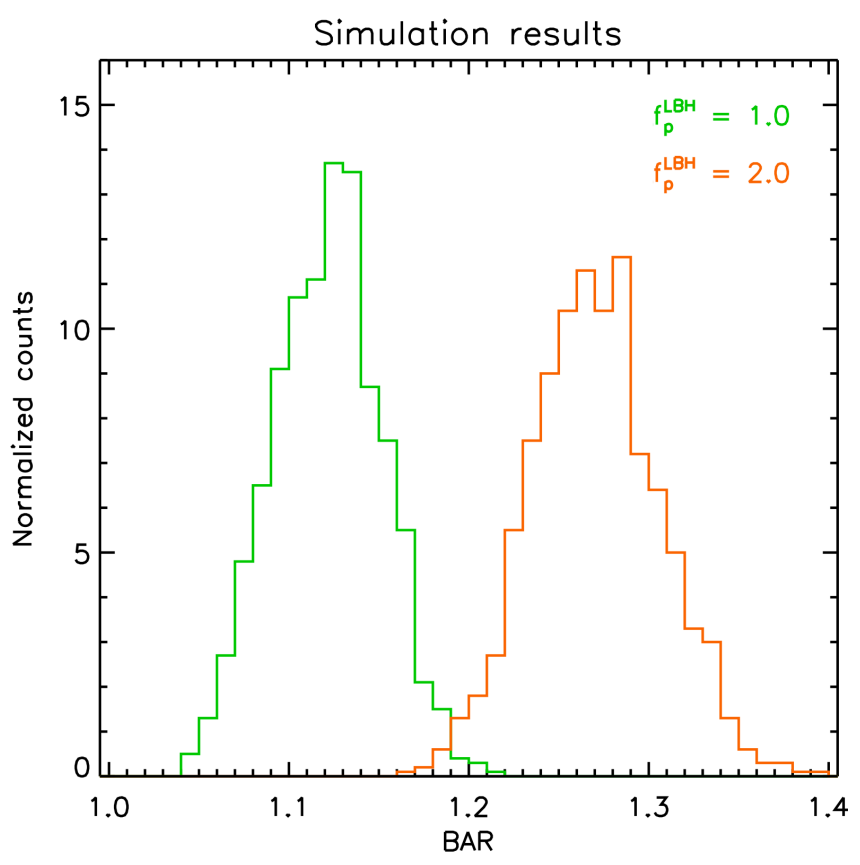

Figure A1. Histograms of below-to-above ratios (BAR; defined in Sect. 4.1) from 1000 randomized simulation runs (each) for $\mathrm{f}_{\mathrm{p}}^{\mathrm{LBH}}=$ 10 (green) and $\mathrm{f}_{\mathrm{p}}^{\mathrm{LBH}}=20$ (orange). The counts (i.e., numbers of BAR statistics that fall in each histogram bin) are normalized so that the integrated area under each curve equals unity.

time of the satellite observation or vice versa. (Some details are omitted here, but the author will provide the missing details on request.) The proton auroral contributions to the simulated LBHS and LBHL values are multiplied by $\mathrm{f}_{\mathrm{p}}^{\mathrm{LBH}}$. Additionally, the simulated emission values are modified by sampling from Poisson noise distributions to represent the random effects of counting statistics, using appropriate responsivities (see Sect. 2.1) and accounting for geocorona in the case of HI $121.6 \mathrm{~nm}$.

Once the ground station $\mathrm{NmE}$ and satellite-observed emission values have been generated as just described, FUVderived $\mathrm{NmE}$ is computed from the simulated LBHS and LBHL values using the two-channel auroral FUV remote sensing algorithm described in Knight et al. (2018) Sect. 2.3. Finally, the BAR statistic is computed in exactly the same way as described in Sect. 4.1. A total of 1000 of the abovedescribed runs were done for $\mathrm{f}_{\mathrm{p}}^{\mathrm{LBH}}=1.0$ and $\mathrm{f}_{\mathrm{p}}^{\mathrm{LBH}}=2.0$ (each), with the BAR values saved for analysis. Normalized histograms showing the distributions of BAR statistics obtained this way are shown in Fig. A1.

The means of the BAR statistics for $\mathrm{f}_{\mathrm{p}}^{\mathrm{LBH}}=1.0$ and 2.0 are 1.121 and 1.271, respectively, and the standard deviations are 0.030 and 0.036 , respectively. The results for $\mathrm{f}_{\mathrm{p}}^{\mathrm{LBH}}=1.0$ correspond to the hypothesis that the $\mathrm{B} 3 \mathrm{C}$-predicted emission yields and $\mathrm{NmE}$ values for electron and proton aurora are correct, and the results for $\mathrm{f}_{\mathrm{p}}^{\mathrm{LBH}}=2.0$ correspond to the hypothesis that the $\mathrm{B} 3 \mathrm{C}$ proton auroral $\mathrm{LBH}$ emission yields 
need to be increased by a factor of $\sim 2.0$, as suggested by earlier in situ comparison results described in Sect. 3.

Evidently, the BAR statistics of 1.012 and 0.974 for the pre-coincidence and post-coincidence comparisons described in Sect. 4.1 are below all of the BAR statistics obtained for the 1000 simulation runs generated for $\mathrm{f}_{\mathrm{p}}^{\mathrm{LBH}}=$ 1.0 and even farther below the BAR statistics obtained for $\mathrm{f}_{\mathrm{p}}^{\mathrm{LBH}}=2.0$. Possible reasons for this surprising result related to $\mathrm{B} 3 \mathrm{C}$ model assumptions, the possible sources of error in the earlier in situ comparisons, and the nature of FUVionosonde comparisons, are discussed in Sect. 4.2.

Considering possible explanations more specific to the simulation, it could be suggested that higher BAR statistics are found in the simulation than in the actual FUV-ionosonde comparisons because the precipitating electron and proton fluxes observed by POES 17 in 2003 and 2004 are not consistent with those occurring at the actual overpasses of the ground stations by the three satellites. It can be seen in Table 2 of Knight et al. (2018) that about two-thirds of the overflights included in our study occurred from 2002 to 2007, during the descending phase of solar cycle 23 , so the prevailing conditions should be similar. There was insufficient time to generate simulations based on observations made by other POES satellites in other years. 
Code availability. The routines for visualization, data analysis, and statistical simulation are available from the author upon request.

Data availability. Ground station ionosonde data were provide by the Global Ionosphere Radio Observatory (GIRO) and are available at http://giro.uml.edu/ (University of Massachusetts Lowell, 2021). FUV L1B data may be obtained from http://guvitimed.jhuapl.edu/ (Johns Hopkins University Applied Physics Laboratory, 2021a) and http://ssusi.jhuapl.edu/ (Johns Hopkins University Applied Physics Laboratory, 2021b). All of the coincident FUV/ionosonde data values used in this work are provided at the website http://www.cpi. com/projects/fuvi.html (Computational Physics, Inc., 2021).

Author contributions. HK carried out the analysis described herein.

Competing interests. The author declares that there is no conflict of interest.

Acknowledgements. This work was funded by NASA (grant no. NNX13AF41G). The author acknowledges the operators of the Digisondes at Goose Bay and Gakona (both operated by the US Air Force) and Troms $\varnothing$ (operated and funded in part by QinetiQ). The study used the Norilsk ionosonde data of the Center for Common Use called Angara (http://ckp-rf.ru/ckp/3056, last access: 18 January 2021), which was obtained with budgetary funding of Basic Research Program II.12. The author acknowledges GIRO (http://spase.info/SMWG/Observatory/GIRO, last access: 18 January 2021).

The author thanks Doug Strickland for reading the paper and making some helpful suggestions.

Financial support. This research has been supported by the National Aeronautics and Space Administration (grant no. NNX13AF41G).

Review statement. This paper was edited by Dalia Buresova and reviewed by three anonymous referees.

\section{References}

Aerospace Corporation, Naval Research Laboratory, Johns Hopkins Applied Physics Laboratory, Air Force Research Laboratory, George Mason University, Computational Physics, Inc., SRI International, and Boston College: Calibration/Validation Final Report for the Special Sensor Ultraviolet Limb Imager (SSULI) and the Special Sensor Ultraviolet Spectrographic Imager (SSUSI) on the Defense Meteorological Satellite Program (DMSP) F16 Spacecraft, Attn: SMC/RS, Space and Missile Systems Center, Air Force Space Command, 483 N. Aviation Blvd., El Segundo, CA 90245-2808, USA, 2006.
Aerospace Corporation, Naval Research Laboratory, Johns Hopkins Applied Physics Laboratory, Air Force Research Laboratory, Computational Physics, Inc., SRI International, and Boston College: Calibration/Validation Final Report for the Special Sensor Ultraviolet Limb Imager (SSULI) and the Special Sensor Ultraviolet Spectrographic Imager (SSUSI) on the Defense Meteorological Satellite Program (DMSP) F18 Spacecraft, Aerospace Report No. TOR-2012(1550)-5, Attn: SMC/RS, Space and Missile Systems Center, Air Force Space Command, 483 N. Aviation Blvd., El Segundo, CA 90245-2808, USA, 2011.

Aksnes, A., Stadsnes, J., Bjordal, J., Østgaard, N., Vondrak, R. R., Detrick, D. L., Rosenberg, T. J., Germany, G. A., and Chenette, D.: Instantaneous ionospheric global conductance maps during an isolated substorm, Ann. Geophys., 20, 1181-1191, 2002.

Baker, J. B. H., Zhang, Y., Greenwald, R. A., Paxton, L. J., and Morrison D.: Height-integrated Joule and auroral particle heating in the nightside high-latitude thermosphere, Geophys. Res. Lett., 31, L09807, https://doi.org/10.1029/2004GL019535, 2004.

Basu, B., Jasperse, J. R., Robinson, R. M., Vondrak, R. R., and Evans, D. S.: Linear transport theory of auroral proton precipitation: A comparison with observations, J. Geophys. Res., 92, 5920-5932, 1987.

Brittnacher, M., Elsen, R., Park, G., Chen, L., Germany, G., and Spann, J.: A dayside auroral energy deposition case study using the Polar Ultraviolet Imager, Geophys. Res. Lett., 24, 991-994, 1997.

Christensen, A. B., Paxton, L. J., Avery, A., Craven, J., Crowley, G., Jumm, D. C., Kil, H., Meier, R. R., Meng, C.-I., Morrison, D., Ogorzalek, B. S., Straus, P., Strickland, D. J., Swenson, R. M., Walterscheid, R. L., Wolven, B., and Zhang, Y.: Initial observations with the Global Ultraviolet Imager (GUVI) in the NASA TIMED satellite mission, J. Geophys. Res., 108, 14511466, https://doi.org/10.1029/2003JA009918, 2003.

Computational Physics, Inc.: Auroral FUV Ionosonde, available at: https://www.cpi.com/projects/fuvi.html, last access: 18 January 2021.

Correira, J. T., Strickland, D. J., Evans, J. S., Knight, H. K., and Hecht, J. H.: A downward revision of a recently reported proton auroral LBH emission efficiency, J. Geophys. Res., 116, A07303, https://doi.org/10.1029/2010JA016016, 2011.

Coumans, V., Gérard, J.-C., Hubert, B., and Evans, D. S.: Electron and proton excitation of the FUV aurora: Simultaneous IMAGE and NOAA observations, J. Geophys. Res., 107, 1347, https://doi.org/10.1029/2001JA009233, 2002.

Coumans, V., Gérard, J.-C., Hubert, B., Meurant, M., and Mende, S. B.: Global auroral conductance distribution due to electron and proton precipitation from IMAGE-FUV observations, Ann. Geophys., 22, 1595-1611, 2004.

Emery, B. A., Coumans, V. C., Evans, D. S., Germany, G. A., Greer, M. S., Holeman, E., Kadinsky-Cade, K., Rich, F. J., and $\mathrm{Xu}, \mathrm{W}$.: Seasonal, $\mathrm{Kp}$, solar wind, and solar flux variations in long-term singlepass satellite estimates of electron and ion auroral hemispheric power, J. Geophys. Res., 113, https://doi.org/10.1029/2007JA012866, 2008.

Evans, D. S. and Greer, M. S.: Polar Orbiting Environmental Satellite Space Environment Monitor: 2. Instrument descriptions and archive data documentation, version 1.4, NOAA technical memorandum, Space Environ. Cent., Boulder, Colorado, 2004. 
Fang, X., Liemohn, M. W., Kozyra, J. U., Evans, D. S., and DeJong, A. D.: Global $30-240 \mathrm{keV}$ proton precipitation in the 17-18 April 2002 geomagnetic storms: 2. Conductances and beam spreading, J. Geophys. Res., 112, A05302, https://doi.org/10.1029/2006JA012113, 2007.

Frey, H. U., Mende, S. B., Carlson, C. W., Gérard, J.-C., Hubert, B., Spann, J., Gladstone, R., and Immel, T. J.: The electron and proton aurora as seen by IMAGE-FUV and FAST, Geophys. Res. Lett., 28, 1135-1138, 2001.

Galand, M. and Lummerzheim, D.: Contribution of proton precipitation to space-based auroral FUV observations, J. Geophys. Res., 109, A03307, https://doi.org/10.1029/2003JA010321, 2004.

Galand, M. and Richmond, A. D.: Ionospheric electrical conductances produced by auroral proton precipitation, J. Geophys. Res., 106, 117-125, 2001.

Gelinas, L. J. and Hecht, J. H.: Calibration/validation final report for the Special Sensor Ultraviolet Limb Imager (SSULI) and the Special Sensor Ultraviolet Spectrographic Imager (SSUSI) on the Defense Meteorological Satellite Program (DMSP) F19 Spacecraft, Aerospace Report No. TOR-2016-00996, Attn: SMC/RS, Space and Missile Systems Center, Air Force Space Command, 483 N. Aviation Blvd., El Segundo, CA, USA, 90245-2808, 2016

Gérard, J.-C., Hubert, B., Meurant, M., Shematovich, V. I., Bisikalo, D. V., Frey, H., Mende, S., Gladstone, G. R., and Carlson, C. W.: Observation of the proton aurora with IMAGE FUV imager and simultaneous ion flux in situ measurements, J. Geophys. Res., 106, 28939-28948, 2001.

Hardy, D. A., Gussenhoven, M. S., and Brautigam, D.: A statistical model of auroral ion precipitation, J. Geophys. Res., 94, 370392, 1989.

Hubert, B., Gérard, J.-C., Bisikalo, D. V., Shematovich, V. I., and Solomon, S. C.: The role of proton precipitation in the excitation of auroral FUV emissions, J. Geophys. Res., 106, 21475-21494, 2001.

Hubert, B., Gérard, J. C., Evans, D. S., Meurant, M., Mende, S. B., Frey, H. U., and Immel, T. J.: Total electron and proton energy input during auroral substorms: Remote sensing with IMAGE-FUV, J. Geophys. Res., 107, 1183, https://doi.org/10.1029/2001JA009229, 2002.

Johns Hopkins University Applied Physics Laboratory: Global Ultraviolet Imager, available at: http://guvitimed.jhuapl.edu, last access: 18 January 2021a.

Johns Hopkins University Applied Physics Laboratory: Special Sensor Ultraviolet Spectrographic Imager, available at: http:// ssusi.jhuapl.edu, last access: 18 January 2021b.

Knight, H. K., Strickland, D. J., Hecht, J. H., Straus, P. R., Morrison, D., Paxton, L. J., and Evans, D. S.: Evidence for significantly greater $\mathrm{N}_{2}$ Lyman-Birge-Hopfield emission efficiencies in proton versus electron aurora based on analysis of coincident DMSP SSUSI and SSJ/5 data, J. Geophys. Res., 113, A04305, https://doi.org/10.1029/2007JA012728, 2008.

Knight, H. K., Strickland, D. J., Correira, J., Hecht, J. H., and Straus, P. R.: An empirical determination of proton auroral far ultraviolet emission efficiencies using a new non-climatological proton flux extrapolation method, J. Geophys. Res., 117, A11316, https://doi.org/10.1029/2012JA017672, 2012.
Knight, H. K., Galkin, I. A., Reinisch, B. W., and Zhang, Y.: Auroral ionospheric $\mathrm{E}$ region parameters obtained from satellite-based far ultraviolet and ground-based ionosonde observations: Data, methods, and comparisons, J. Geophys. Res., 123, 6065-6089, https://doi.org/10.1029/2017JA024822, 2018.

Liou, K., Newell, P. T., Meng, C. I., Brittnacher, M., and Parks, G.: Characteristics of the solar wind controlled auroral emissions, J. Geophys. Res., 103, 17543- 17557, 1998.

Luan, X., Wang, W., Burns, A. G., Solomon, S. C., Zhang, Y., and Paxton, L. J.: Seasonal and hemispheric variations of the total auroral precipitation energy flux from TIMED/GUVI, J. Geophys. Res., 115, A11304, https://doi.org/10.1029/2009JA015063, 2010.

Newell, P. T., Liou, K., Sotirelis, T., and Meng, C. I.: Polar Ultraviolet Imager observations of global auroral power as a function of polar cap size and magnetotail stretching, J. Geophys. Res., 106, 5895-5905, 2001.

Newell, P. T., Sotirelis, T., and Wing, S.: Diffuse, monoenergetic, and broadband aurora: The global precipitation budget, J. Geophys. Res., 114, A09207, https://doi.org/10.1029/2009JA014326, 2009.

Paxton, L. J., Morrison, D., Zhang, Y., Kil, H., Wolven, B., Ogorzalek, B. S., Humm, D., and Meng, C.-I.: Validation of remote sensing products produced by the special sensor ultraviolet scanning imager (SSUSI) - a far-UV imaging spectrograph on DMSP F16, Optical Spectroscopy Techniques, Remote Sensing, and Instrumentation for Atmospheric and Space Research IV, 4485, 338348, 2002.

Reinisch, B. W.: Modern Ionosondes, in: Modern Ionospheric Science, edited by: Kohl, H., Rüster, R., and Schlegel, K., European Geophysical Society, 37191 Katlenburg-Lindau, Germany, 440458, 1996.

Reinisch, B. W., Galkin, I. A., Khmyrov, G. M., Kozlov, A. V., Bibl, K., Lisysyan, I. A., Cheney, G. P., Huang, X., Kitrosser, D. F., Paznukhov, V. V., Luo, Y., Jones, W., Stelmash, S., Hamel, R., and Grochmal, J.: New Digisonde for Research and Monitoring Applications, Radio Sci., 44 RS0A24, https://doi.org/10.1029/2008RS004115, 2009.

Rencher, A. C. and Schaalje, G. B.: Linear Models in Statistics, John Wiley and Sons, Inc., Hoboken, NJ, USA, 2008.

Strickland, D. J., Daniell Jr, R. E., Basu, B., and Jasperse, J. R.: Transport-theoretic model for the electron-proton-hydrogen atom aurora: 2. Model results, J. Geophys. Res., 98, 2153321548, 1993.

University of Massachusetts Lowell: Global Ionospheric Radio Observatory, available at: http://giro.uml.edu/, last access: 18 January 2021.

Van der Vaart, A. W.: Asymptotic Statistics, Cambridge University Press, Cambridge, UK, 1998.

Zhang, Y. and Paxton, L. J.: An empirical Kp-dependent global auroral model based on TIMED/GUVI data, J. Atmos. Sol.-Terr. Phy. 70, 1231-1242, 2008.

Zhang, Y., Paxton, L. J., Bilitza, D., and Doe, R.: Near realtime assimilation in IRI of auroral peak E-region density and equatorward boundary, Adv. Space Res., 46, 1055-1063, https://doi.org/10.1016/j.asr.2010.06.029, 2010. 